\title{
Antimicrobial Susceptibility of Staphylococcus aureus, Streptococcus agalactiae, and Escherichia coli Isolated from Mastitic Dairy Cattle in Ukraine
}

\author{
Leta Elias ${ }^{1}$, Ajay S. Balasubramanyam ${ }^{2}$, Olena Y. Ayshpur ${ }^{3}$, Iryna U. Mushtuk ${ }^{3}$, \\ Nataliya O. Sheremet ${ }^{3}$, Volodymyr V. Gumeniuk ${ }^{3}$, Jeffrey M. B. Musser ${ }^{1}$ and \\ Artem S. Rogovskyy $1, *$ (D) \\ 1 Department of Veterinary Pathobiology, College of Veterinary Medicine and Biomedical Sciences, \\ Texas A\&M University, College Station, TX 77843, USA; le227@cornell.edu (L.E.); \\ jmusser@cvm.tamu.edu (J.M.B.M.) \\ 2 College of Osteopathic Medicine, Kansas City University of Medicine and Biosciences, \\ 2901 St. John's Boulevard, Joplin, MO 64804, USA; abalasubramanyam@kcumb.edu \\ 3 Institute of Veterinary Medicine of the National Academy of Agrarian Sciences of Ukraine, 30 Donetska Str., \\ Kyiv 03151, Ukraine; olenaayshpur@gmail.com (O.Y.A.); mushtuk0104@gmail.com (I.U.M.); \\ seremet-2@ukr.net (N.O.S.); Volodymyr.Gumeniuk@arterium.ua (V.V.G.) \\ * Correspondence: arogovskyy@tamu.edu
}

Received: 3 July 2020; Accepted: 29 July 2020; Published: 1 August 2020

\begin{abstract}
Bovine mastitis is the predominant cause for antimicrobial use on dairy farms and is a major source of economic losses in the dairy industry. In this study, the antimicrobial susceptibility profiles of common mastitis-causing pathogens, Staphylococcus aureus $(n=62)$, Streptococcus agalactiae $(n=46)$, and Escherichia coli $(n=129)$, were determined for dairy cattle with mastitis across 142 Ukrainian farms. The results showed that there were more gentamicin resistant S. aureus isolates $(16.95 \%)$ identified in this study than previously reported for Ukrainian dairy cattle. Moreover, low levels of amoxicillin susceptibly (13.51\%) were observed for St. agalactiae, which contrasted a previous study showing susceptibility levels of $>50 \%$. St. agalactiae resistance to tetracycline was observed in $80 \%$ of the isolates. Cephalosporin use was most ineffective against $E$. coli, with $43.27-56 \%$ of the isolates exhibiting this resistant trait. Overall, this study performed a preliminary analysis of antimicrobial resistance on mastitis isolates from Ukrainian farms. However, given the limited numbers of the isolates tested in this study and that the publications on antimicrobial resistance in animal husbandry of Ukraine are very few, more extensive investigations are needed to comprehensively examine susceptibility patterns of mastitis-causing pathogens in dairy cattle in Ukraine.
\end{abstract}

Keywords: antimicrobial resistance; dairy farms; mastitis; bacterial isolates; Ukraine

\section{Introduction}

Bovine mastitis is one of the most prevalent conditions affecting dairy cattle and is the most frequent reason for antimicrobial use on dairy farms. Consequently, mastitis is a significant economic burden to the dairy industry [1,2]. Although Escherichia coli, Staphylococcus aureus, and Streptococcus agalactiae are considered some of the main mastitis-causing pathogens, many other bacterial species can be implicated [1-4]. Due to the bacterial diversity associated with bovine mastitis, and the fact that pathogen identification is not frequently performed for mastitic dairy cattle, antimicrobials with a broad spectrum of activity against both gram-negative and gram-positive organisms are routinely used in dairy medicine [1,5]. As a result of decades-long usage of antimicrobials to date, bacterial resistance is an increasing concern in, and beyond, veterinary medicine $[2,6,7]$. Monitoring susceptibility patterns 
of clinical isolates is a significant aspect of the One Health approach [8,9]. Some studies advocate the use of susceptibility testing for rationally selecting the most appropriate agents to counter mastitis infections, although the accuracy of in vitro susceptibility testing is limited in its ability to predict the curability of mastitis [1,10-13]. Nonetheless, it is recommended within the European Commission's guidelines for the prudent use of antimicrobials in veterinary medicine that susceptibility testing be performed prior to mastitis treatment with antimicrobials to prevent the propagation of resistant bacteria via rationalized selection of an appropriate antimicrobial [10,11,14].

Given that there are almost no peer-reviewed publications on antimicrobial resistance in animal husbandry of Ukraine [15-17], the aim of this study was to assess the antimicrobial susceptibility patterns of mastitis-causing pathogens, specifically, E. coli, S. aureus, and St. agalactiae isolated from dairy cattle with mastitis in Ukraine.

\section{Results}

In this study, $13.0 \%$ (isolates/total isolates; 132/1017) of the isolates were identified as S. aureus, and susceptibility testing was performed for only $62 \mathrm{~S}$. aureus isolates due to very limited resources. Gentamicin was mostly active against the $S$. aureus isolates, with a proportion of $16.95 \%$ (number of isolates/total isolates tested; 10/59) resistant isolates (Table 1). Against tetracycline, $21.43 \%(6 / 28)$ of the isolates were resistant. As for ofloxacin, 26.32\% (5/19) of the S. aureus isolates were resistant. Antimicrobial susceptibility testing was also performed for the cephalosporins ceftiofur and cefotaxime. Against these cephalosporins, $41.51 \%$ (22/53) and $47.06 \%$ (8/17) of the isolates showed resistance to ceftiofur and cefotaxime, respectively (Table 1 ).

St. agalactiae accounted for $11.0 \%$ (112/1017) of the total isolates collected in this study, and of those, 46 were tested for antimicrobial susceptibility. Susceptibility testing revealed that a low proportion $(13.51 \% ; 5 / 37)$ were susceptible to amoxicillin (Table 1). Cefotaxime was moderately effective against $S t$. agalactiae, as susceptibility was observed in $41.18 \%$ (7/17) of the isolates tested. Against ceftiofur, the proportion of resistant isolates was $25.58 \%$ (11/43). Ofloxacin was mostly effective against $S t$. agalactiae, with a moderately low proportion of the isolates being resistant to this antimicrobial $(17.65 \% ; 3 / 17)$ (Table 1). Lastly, there were no Clinical and Laboratory Standards Institute (CLSI) interpretive criteria for gentamicin, but the zone diameters were included in Tables S1 and S2.

E. coli was identified in $23.12 \%$ (235/1017) of the total bacterial isolates collected in this study, and susceptibility testing was performed for 129 isolates (Table 1). Amoxicillin had poor activity against the E. coli isolates, with $77.45 \%$ (79/102) testing resistant to this antimicrobial. Cefotaxime resistance was present in over half of the isolates tested $(56.25 \% ; 27 / 48)$. In comparison, ceftiofur was slightly more active against $E$. coli, with $43.27 \%$ (45/104) being resistant to this drug (Table 1). Of the isolates tested against ofloxacin, 26.92\% (14/52) exhibited resistance. Tetracycline was mostly effective against $E$. coli, with $18.75 \%$ (9/48) of the isolates showing this resistant trait. Against gentamicin, $26.27 \%(31 / 118)$ of the isolates were resistant to this antimicrobial (Table 1). 
Table 1. Antimicrobial susceptibility of bacterial isolates from Ukrainian dairy cattle with mastitis.

\begin{tabular}{|c|c|c|c|c|c|c|c|}
\hline \multicolumn{8}{|c|}{ Staphylococcus aureus Isolates } \\
\hline Antimicrobials* & Isolates tested & \# Resistant & $\%$ Resistant & \# Susceptible & $\%$ Susceptible & \# Intermediate & $\%$ Intermediate \\
\hline Amoxicillin & 57 & - & - & - & - & - & - \\
\hline Cefotaxime ${ }^{* *}$ & 17 & 8 & 47.06 & 4 & 23.53 & 5 & 29.41 \\
\hline Ceftiofur & 53 & 22 & 41.51 & 17 & 32.08 & 14 & 26.42 \\
\hline Gentamicin & 59 & 10 & 16.95 & 46 & 77.97 & 3 & 5.08 \\
\hline Ofloxacin & 19 & 5 & 26.32 & 11 & 57.89 & 3 & 15.79 \\
\hline Tetracycline & 28 & 6 & 21.43 & 14 & 50.00 & 8 & 28.57 \\
\hline \multicolumn{8}{|c|}{ Streptococcus agalactiae Isolates } \\
\hline Antimicrobials * & Isolates tested & \# Resistant & $\%$ Resistant & \# Susceptible & $\%$ Susceptible & \# Intermediate & $\%$ Intermediate \\
\hline Amoxicillin & 37 & - & - & 5 & 13.51 & - & - \\
\hline Cefotaxime & 17 & - & - & 7 & 41.18 & - & - \\
\hline Ceftiofur & 43 & 11 & 25.58 & 20 & 46.51 & 12 & 27.91 \\
\hline Gentamicin & 39 & - & - & - & - & - & - \\
\hline Ofloxacin & 17 & 3 & 17.65 & 8 & 47.06 & 6 & 35.29 \\
\hline Tetracycline & 10 & 8 & 80.00 & 2 & 20.00 & 0 & 0.00 \\
\hline \multicolumn{8}{|c|}{ Escherichia coli Isolates } \\
\hline Antimicrobials * & Isolates tested & \# Resistant & $\%$ Resistant & \# Susceptible & \% Susceptible & \# Intermediate & $\%$ Intermediate \\
\hline Cefotaxime & 48 & 27 & 56.25 & 6 & 12.50 & 15 & 31.25 \\
\hline Ceftiofur & 104 & 45 & 43.27 & 22 & 21.15 & 37 & 35.58 \\
\hline Gentamicin & 118 & 31 & 26.27 & 56 & 47.46 & 31 & 26.27 \\
\hline Ofloxacin & 52 & 14 & 26.92 & 34 & 65.38 & 4 & 7.69 \\
\hline Tetracycline & 48 & 9 & 18.75 & 32 & 66.67 & 7 & 14.58 \\
\hline
\end{tabular}

$\left(^{*}\right)$ The interpretation of minimum inhibitory zones was based on the 2019 Clinical and Laboratory Standards Institute (CLSI) guideline M100 with the exception of ceftiofur, for which veterinary CLSI breakpoints (CLSI guideline VET08) were used. $\left.{ }^{* *}\right)$ Susceptibility or resistance of S. aureus isolates to cefotaxime was predicted by interpreting the respective results for ceftiofur. (-) Interpretation was not performed because there were no clinical breakpoints. 


\section{Discussion}

Our results indicated that there was a wide variability in the antimicrobial susceptibilities of S. aureus, St. agalactiae, and E. coli isolated from dairy cattle with mastitis in Ukraine. Overall, the three pathogens exhibited a high level of resistance to the beta-lactam antimicrobials, amoxicillin, cefotaxime, and ceftiofur. In this study, only $13.51 \%$ of the St. agalactiae isolates were susceptible to amoxicillin. In comparison, the previous Ukrainian bovine mastitis study demonstrated that approximately half of the St. agalactiae isolates were susceptible to amoxicillin [15].

The resistance of the mastitis isolates to amoxicillin and the cephalosporins, cefotaxime and ceftiofur, was high for $S$. aureus and E. coli. This was comparable to reports for $S$. aureus from mastitis cases recorded for Europe and the United States, where beta-lactamase producers were identified in $35.1 \%$ of $S$. aureus isolates [18]. In contrast, a previous mastitis antimicrobial resistance study performed across European dairy farms reported that $S$. aureus and E. coli resistance to ceftiofur was identified in only $1 \%$ of the isolates [19]. To date, despite a growing prevalence of resistant bacteria, amoxicillin continues to be among the four most commonly used antimicrobials in veterinary medicine to treat E. coli and S. aureus infections in Ukraine [20].

The high proportion of ceftiofur- and cefotaxime-resistant E. coli isolates identified in the current study suggested that extended-spectrum beta-lactamase producing strains may be circulating across the investigated dairy farms, an important knowledge gap that warrants further investigation. This finding could potentially be explained by the unrestricted use of extended-spectrum cephalosporins in rural farming of Ukraine, and more specifically by the preferred use of these antimicrobials for treatment of bovine mastitis [21,22].

In light of the significant health threat posed by methicillin-resistant S. aureus (MRSA) in Europe, as well as globally, monitoring the prevalence of $S$. aureus infections among production animals would be warranted $[23,24]$. To date, only three cases of MRSA have been reported by a previous dairy cattle study within Dnipropetrovsk and Donetsk regions, Ukraine [17]. Unfortunately, there is no program to monitor the prevalence of staphylococcal infections among animals in Ukraine to date.

Gentamicin is among the leading antimicrobials used to combat animal infections, in general, of S. aureus and E. coli in Ukraine [20]. The overall effectiveness of gentamicin, as demonstrated in this study by the in vitro susceptibility of the mastitis isolates, may be a reason for its usage. Gentamicin usage in food animals, however, is carefully regulated in the European Union, and the European Commission has set limits on the allowable gentamicin residues found in animal food products [25]. It is worth noting that whereas $16.95 \%$ of the S. aureus isolates were resistant to gentamicin in this study, much fewer resistant $S$. aureus isolates were identified by a previous Ukrainian study in which only 2 of 62 mastitis isolates tested resistant to this aminoglycoside [16]. In agreement with this earlier Ukrainian bovine mastitis study, in the current investigation, tetracycline effectively suppressed $S$. aureus growth in vitro [16]. In the present study, tetracycline was also found to be highly efficacious against E. coli isolates, whereas resistance to this antimicrobial was frequently observed among St. agalactiae, with $80 \%$ of the isolates demonstrating this resistance trait. The latter is in concordance with previous studies, where resistance to tetracycline was frequently detected among St. agalactiae isolates $[15,26,27]$. Although the antimicrobial susceptibility profile of St. agalactiae was difficult to evaluate due to a lack of CLSI breakpoints, in general it is considered highly responsive to almost all antimicrobial treatment regimens [1].

Unfortunately, in Ukraine to date, there are no established mastitis treatment protocols, despite the fact that attention in this area has indeed grown since the country joined the World Trade Organization (WTO) in 2008 [28]. Additionally, prior to 2018, antimicrobial usage in Ukraine was mostly unregulated, as there was no national body or organization overseeing the consumption and application of these agents [29]. Given that there is a very limited number of studies that have evaluated the antimicrobial susceptibility patterns of $S$. aureus, St. agalactiae, and E. coli isolated from mastitic dairy cattle from Ukrainian farms, future investigations are highly warranted to assess and monitor in real time the 
status of antimicrobial resistance in animal husbandry of Ukraine, and to observe the effect of the recent antimicrobial policy initiatives in the future.

\section{Materials and Methods}

In the present study, bacteria were cultured from milk samples of mastitic dairy cattle as part of a routine diagnostic service provided to dairy farms in Ukraine. Between 2016 and 2018, a total of 142 farms located across various regions of Ukraine were included in this study. These year-round farms had a herd size of 500-4500 cattle (Holstein Friesians, Red Steppe, Ayrshire, Simmental, Black Red, and Jersey), of which 200-2000 animals were milking cows. The operations were equipped with various types of parlors and other milking equipment (Bratslav, Ukraine, DeLaval, Sweden; GEA, Germany).

Primary isolation was performed by inoculation of $10 \mu \mathrm{L}$ of milk to Trypticase soy agar with $5 \%$ bovine blood and $0.1 \%$ esculin, and the cultures were incubated for $48 \mathrm{~h}$ at $37^{\circ} \mathrm{C}$. The genus and species of the isolates were identified based on colony morphology, Gram stain, and biochemical analysis (API ${ }^{\circledR} 20 \mathrm{E}$, BioMeriex, France). In total, 1017 bacterial isolates were identified, including E. coli $(n=235)$, S. aureus $(n=132)$, and St. agalactiae $(n=112)$. Unfortunately, due to limited resources, only 129 E. coli isolates from 88 farms, 68 S. aureus isolates from 55 farms, and 46 St. agalactiae isolates from 44 farms were tested for antimicrobial susceptibility. Antimicrobial susceptibility testing was performed on randomly selected isolates via the disc diffusion method [30] for the following antimicrobial agents: amoxicillin $(20 \mu \mathrm{g})$, cefotaxime $(30 \mu \mathrm{g})$, ceftiofur $(30 \mu \mathrm{g})$, gentamicin $(10 \mu \mathrm{g})$, ofloxacin $(5 \mu \mathrm{g})$, and tetracycline ( $30 \mu \mathrm{g})$ (Pharmactiv, Ukraine). The test results were interpreted by using human breakpoints for all the antimicrobial agents except for ceftiofur, for which veterinary interpretive criteria for cattle were used (Tables S1 and S2) [31,32].

Supplementary Materials: The following are available online at http://www.mdpi.com/2079-6382/9/8/469/s1, Table S1: Distribution of minimum inhibitory zones $(\mathrm{mm})$ of pathogens isolated from milk samples, Table S2: Clinical breakpoints used in this study.

Author Contributions: Conceptualization, O.Y.A. and A.S.R.; methodology, I.U.M., N.O.S., V.V.G.; validation, O.Y.A. and A.S.R.; formal analysis, L.E., A.S.B., A.S.R.; resources, O.Y.A. and A.S.R.; writing-original draft preparation, L.E., A.S.B., A.S.R.; writing-review and editing, L.E., J.M.B.M., A.S.B., and A.S.R.; supervision, A.S.R.; funding acquisition, O.Y.A. and A.S.R. All authors have read and agreed to the published version of the manuscript.

Funding: This research received no external funding.

Acknowledgments: The work was partly supported through the Department of Veterinary Pathobiology, Texas A\&M College of Veterinary Medicine and Biomedical Sciences start-up package provided to A.S. Rogovskyy.

Conflicts of Interest: The authors declare no conflicts of interest.

\section{References}

1. Wagner, S.; Erskine, R. Antimicrobial drug use in mastitis. In Antimicrobial Therapy in Veterinary Medicine, 5th ed.; Wiley-Blackwell Publishing: Ames, IA, USA, 2013; pp. 519-528.

2. Minst, K.; Märtlbauer, E.; Miller, T.; Meyer, C. Short communication: Streptococcus species isolated from mastitis milk samples in Germany and their resistance to antimicrobial agents. J. Dairy Sci. 2012, 95, 6957-6962. [CrossRef]

3. Pol, M.; Ruegg, P.L. Treatment practices and quantification of antimicrobial drug usage in conventional and organic dairy farms in wisconsin. J. Dairy Sci. 2007, 90, 249-261. [CrossRef]

4. Tomazi, T.; Coura, F.M.; Gonçalves, J.L.; Heinemann, M.B.; Santos, M.V. Antimicrobial susceptibility patterns of Escherichia coli phylogenetic groups isolated from bovine clinical mastitis. J. Dairy Sci. 2018, 101, 9406-9418. [CrossRef]

5. Martins, S.A.M.; Martins, V.C.; Cardoso, F.A.; Germano, J.; Rodrigues, M.; Duarte, C.; Bexiga, R.; Cardoso, S.; Freitas, P.P. Biosensors for on-farm diagnosis of mastitis. Front. Bioeng. Biotechnol. 2019, 7, 186. [CrossRef]

6. Stefan, S.; Elisabeth, C.-D. Use of antimicrobials in veterinary medicine and mechanisms of resistance. Vet. Res. 2001, 32, 201-225. 
7. Denamiel, G.; Llorente, P.; Carabella, M.; Rebuelto, M.; Gentilini, E. Anti-microbial susceptibility of Streptococcus spp. isolated from bovine mastitis in Argentina. J. Vet. Med. Ser. B 2005, 52, 125-128. [CrossRef] [PubMed]

8. Correia, S.; Silva, V.; García-Díez, J.; Teixeira, P.; Pimenta, K.; Tejedor-Junco, M.T.; Oliveira, S.; Igrejas, G.; Poeta, P. Absence of methicillin-resistant Staphylococcus aureus (MRSA) in cattle from Portugal: A One Health approach. Infect. Drug Resist. 2019, 12, 3421-3423. [CrossRef] [PubMed]

9. Boqvist, S.; Söderqvist, K.; Vågsholm, I. Food safety challenges and One Health within Europe. Acta Vet. Scand. 2018, 60, 1. [CrossRef]

10. Moroni, P.; Pisoni, G.; Antonini, M.; Villa, R.; Boettcher, P.; Carli, S. Short communication: Antimicrobial drug susceptibility of Staphylococcus aureus from subclinical bovine mastitis in Italy. J. Dairy Sci. 2006, 89, 2973-2976. [CrossRef]

11. Bengtsson, B.; Unnerstad, H.E.; Ekman, T.; Artursson, K.; Nilsson-Öst, M.; Waller, K.P. Antimicrobial susceptibility of udder pathogens from cases of acute clinical mastitis in dairy cows. Vet. Microbiol. 2009, 136, 142-149. [CrossRef]

12. Apparao, D.; Oliveira, L.; Ruegg, P.L. Relationship between results of in vitro susceptibility tests and outcomes following treatment with pirlimycin hydrochloride in cows with subclinical mastitis associated with Gram-positive pathogens. J. Am. Vet. Med. Assoc. 2009, 234, 1437-1446. [CrossRef] [PubMed]

13. Constable, P.D.; Morin, D.E. Treatment of clinical mastitis: Using antimicrobial susceptibility profiles for treatment decisions. Vet. Clin. N. Am. Food A 2003, 19, 139-155. [CrossRef]

14. Commission Notice. In Guidelines for the Prudent Use of Antimicrobials in Veterinary Medicine; Publications Office of the European Union: Luxembourg, 2015; Volume 299, pp. 10-12.

15. Horiuk, Y.; Kukhtyn, M.; Kovalenko, V.; Kornienko, L.; Horiuk, V.; Liniichuk, N. Biofilm formation in bovine mastitis pathogens and the effect on them of antimicrobial drugs. Indep. J. Manag. Prod. 2019, 10, 897. [CrossRef]

16. Bergilevich, A.; Kasianchuk, V.; Kukhtyn, M.; Lotskin, I.; Garkavenko, T.; Shubin, P. Characteristics of antibiotic sensitivity of Staphylococcus aureus isolated from dairy farms in Ukraine. Regul. Mech. Biosyst. 2017, 8, 559-563. [CrossRef]

17. Vishovan, Y.; Ushkalov, V. Spread of staphylococcus and diseases caused by them. Visnyk Agrar. Nauk. 2018, 96, 36-42. [CrossRef]

18. De Oliveira, A.P.; Watts, J.L.; Salmon, S.A.; Aarestrup, F.M. Antimicrobial susceptibility of Staphylococcus aureus isolated from bovine mastitis in Europe and the United States. J. Dairy Sci. 2000, 83, 855-862. [CrossRef]

19. de Jong, A.; El Garch, F.; Simjee, S.; Moyaert, H.; Rose, M.; Youala, M.; Siegwart, E. Monitoring of antimicrobial susceptibility of udder pathogens recovered from cases of clinical mastitis in dairy cows across Europe: VetPath results. Vet. Microbiol. 2018, 213, 73-81. [CrossRef]

20. Salmanov, A.; Iakovlieva, L.; Golubovska, O.; Glushkevych, T. Ukraine Antimicrobial Resistance Update; Poster presented at: World Health Organization Multi-Country AMR Workshop; World Health Organization Regional Office for Europe: Copenhagen, Denmark, 2015.

21. Ali, T.; Rahman, S.U.; Zhang, L.; Shahid, M.; Han, D.; Gao, J.; Zhang, S.; Ruegg, P.L.; Saddique, U.; Han, B. Characteristics and genetic diversity of multi-drug resistant extended-spectrum beta-lactamase (ESBL)-producing Escherichia coli isolated from bovine mastitis. Oncotarget 2017, 8, 90144-90163. [CrossRef]

22. Iakovlieva, L.; Bahlai, T. B-lactam antibiotics in Ukraine: Market and consumption analysis in 2013-2018. SR. Pharm. Sci. 2019, 2, 16-21. [CrossRef]

23. Lee, A.S.; de Lencastre, H.; Garau, J.; Kluytmans, J.; Malhotra-Kumar, S.; Peschel, A.; Harbarth, S. Methicillin-resistant Staphylococcus aureus. Nat. Rev. Dis. Prim. 2018, 4, 18033. [CrossRef]

24. Aires-de-Sousa, M. Methicillin-resistant Staphylococcus aureus among animals: Current overview. Clin. Microbiol. Infect. 2017, 23, 373-380. [CrossRef] [PubMed]

25. Liikanen, E. Commission regulation (EC) No. 868/2002. In Amending Annexes I and II of Council Regulation (EEC) No. 2377/90 Laying Down a Community Procedure for the Establishment of Maximum Residue Limits of Veterinary Medicinal Products in Foodstuffs of Animal Origin; Publications Office of the European Union: Luxembourg, 2002. 
26. Rato, M.G.; Bexiga, R.; Florindo, C.; Cavaco, L.M.; Vilela, C.L.; Santos-Sanches, I. Antimicrobial resistance and molecular epidemiology of streptococci from bovine mastitis. Vet. Microbiol. 2013, 161, 286-294. [CrossRef] [PubMed]

27. Gao, J.; Yu, F.-Q.; Luo, L.-P.; He, J.-Z.; Hou, R.-G.; Zhang, H.-Q.; Li, S.-M.; Su, J.-L.; Han, B. Antibiotic resistance of Streptococcus agalactiae from cows with mastitis. Vet. J. 2012, 194, 423-424. [CrossRef]

28. Stoliuk, V.; Valchuk, O. Mastitis in Ukrainian cows-Effective ways to solve the problem. Inter. Dairy Top. 2011, 10, 13-17.

29. WHO. Ukraine develops National Action Plan on Antimicrobial Resistance. Available online: https://www.euro.who.int/en/health-topics/disease-prevention/antimicrobial-resistance/news/news/ 2018/2/ukraine-develops-national-action-plan-on-antimicrobial-resistance (accessed on 9 December 2019).

30. Bauer, A.W.; Kirby, W.M.M.; Sherris, J.C.; Turck, M. Antibiotic susceptibility testing by a standardized single disk method. Am. J. Clin. Pathol. 1966, 45, 493-496. [CrossRef]

31. CLSI. Performance Standards for Antimicrobial Disk and Dilution Susceptibility Tests for Bacteria Isolated from Animals, 4th ed.; Clinical and Laboratory Standards Institute: Wayne, PA, USA, 2018.

32. CLSI. Performance Standards for Antimicrobial Susceptibility Testing, 29th ed.; Clinical and Laboratory Standards Institute: Wayne, PA, USA, 2019.

(C) 2020 by the authors. Licensee MDPI, Basel, Switzerland. This article is an open access article distributed under the terms and conditions of the Creative Commons Attribution (CC BY) license (http://creativecommons.org/licenses/by/4.0/). 